\title{
03
}

\section{ERRÂNCIA E TRANSGRESSÃO EM CAIM, DE JOSÉ SARAMAGO}

Valéria Aparecida de Souza Machado (PUC Minas)

Recebido em 05 ago 2016. Valéria Aparecida de Souza Machado - Mestre Aprovadoem 11 out 2016. em Literaturas de Língua Portuguesa. Vínculos institucionais: Doutoranda em Literaturas de Língua Portuguesa pela PUC/MG. Bolsista da CAPES. Níveis de atuação: Estudante de doutorado/integrante de grupo de pesquisa/membro de corpo editorial Revista Contraponto. Áreas de atuação: Letras/ Língua Portuguesa/Literatura Brasileira/Literatura Portuguesa. Produção Bibliográfica: O eu e o outro na violência do assalto: (im)possibilidades de constituição subjetiva na e pela linguagem. Revista Crioula (USP), v. 7, p.1-20, 2010/ Ética, estética e política: alteridade e subjetivação em Gaibéus, de Alves Redol. Biblos (Coimbra), v. 11, p.511-527, 2014/ Construção da identidade nacional: outras histórias, outros olhares. Diadorim (Rio de Janeiro), v. 13, p.234-249, 2014. Participação em grupos de pesquisa: Literatura Comparada e polis: rotas alternativas (2011-atual); Leitura para sempre: ampliando redes de leitores (2009-2011); DA RUA: olhares sobre histórias da literatura brasileira (20082011); Programa Nacional Biblioteca na Escola PNBE. 2014. Distinção: Título de Mestre concedido com LOUVOR pela dissertação "O eu e o outro na violência do assalto: vozes e olhares que se (re)velam no espaço do texto". Áreas de interesse: literatura brasileira, literatura portuguesa, literatura africana, 
leitura, produção de texto. Acesso ao CV Lattes: http://lattes.cnpq.br/8767353697713178 Email: mariasouzaval@yahoo.com.br

Resumo: Este artigo tem como objetivo analisar as estratégias de construção e organização textuais utilizadas em Caim, de José Saramago, de modo a discutir aspectos da transgressão operada pelo romance no diálogo com o texto bíblico e sua atualização para outros contextos.

Palavras-chave: Literatura; Estratégias textuais; Diálogo; Transgressão.

Abstract: This article analyses textual strategies of construction and organization used by José Saramago in his book Caim, so as to discuss the way the romance infringes the biblical text of which it takes hold and updates for other contexts.

Key-words: Literature; Textual strategies; Dialogue; Transgression.

A leitura do texto literário requer de seu intérprete um olhar atento e um trabalho afinado de escuta, vez que ele, o texto, não se configura como algo transparente, mas envolvido por tensões de ordem psíquica e subjetiva e por aspectos culturais que engendram todo o processo social.

Alfredo Bosi, em "A interpretação da obra literária" (2003), nos fala do hiato entre o "querer-dizer e o texto ultimado", isto é, entre o evento, tido como aquele acontecer que se torna experiência quando passa pelo sujeito inserido em certo contexto social, e a forma na qual esse evento se encerra. Nesse processo, deparamonos com a "perspectiva" e o "tom", conceitos que o crítico considera essenciais no trabalho de interpretação do texto literário. Por perspectiva entendamos o ponto de vista do sujeito em relação a 
uma experiência social, ou seja, a percepção e o julgamento diante de fatos e situações que envolvem o evento em si. Já o tom designa a "tonalidade afetiva" com que o evento é expresso textualmente.

Ler um texto, pois, não é o mesmo que ler uma informação, dados meramente factuais, nem tampouco fixar-se nas palavras escritas sobre a página como se o texto, voltado apenas para si mesmo, apresentasse, sozinho, todas as possibilidades de resposta. A literatura é, ao mesmo tempo, experiência e ato criativo (Cf. MORAIS, 2004), já que lida com as percepções de um sujeito que escreve em e a partir de um contexto social e, também, com o desejo de fantasia desse mesmo sujeito, advindo de sua passagem pela experiência social. Nesse entremeio a linguagem manifesta-se como forma simbólica de expressão dessa experiência.

Assim, o texto literário, aberto que é às manifestações culturais, sociais e subjetivas, não se faz acabado, mas em constante processo no qual se cruzam e se tensionam sujeitos, vozes e textos diversos. Por isso mesmo, podemos pensar o texto literário como trânsito; trânsito de sujeitos, espaços e tempos, o que nos aproxima do conceito de enunciação. (Cf. WALTY \& PAULINO, 2005). Como nos mostram Bakhtin (1981) e Benveniste (2005), a enunciação pode ser entendida como um ato social e subjetivo de apropriação da linguagem, em que o sujeito depende da interação com o outro para que o processo comunicativo se realize. É, portanto, um processo dialógico, interlocutório, no qual se cruzam uma pluralidade de discursos.

Se tomarmos o texto literário como uma grande cadeia enunciativa, veremos que aí se relacionam não só autor e leitor 
- sujeitos reais - mas sujeitos fictícios, criados pelo texto. Tais sujeitos, veiculando diferentes vozes e discursos, relacionando-se em espaços e tempos diversos, acabam por desvelar conflitos e paradoxos que envolvem as próprias relações sociais. É importante não perder de vista, no entanto, que esse processo operado pelo texto literário é performático, nos termos de Wolfgang Iser (1983; 1996; 2002), já que a literatura não apresenta determinado contexto social tal como ele é, mas assimila situações sociais. O que fica ali encenado é uma outra realidade, criada pelo texto ficcional, numa espécie de jogo com o dado referencial por ele assimilado (Cf. WALTY \& PAULINO, 2005). Nos meandros desse jogo é a própria linguagem que se encena exigindo, na leitura do texto, um olhar capaz de perceber o que está sendo proposto para, então, iniciar-se o processo de construção de sentidos.

Não por acaso a importância de entrarmos no jogo do texto e percebermos, para lá do enunciado, o modo como ele foi construído, quais discursos se cruzam, como se relacionam os sujeitos nos tempos e espaços textuais, não apenas escolhendo, mas, como nos diz Bosi, elegendo "na messe das possibilidades semânticas, apenas aquelas que se movem no encalço da questão crucial: o que o texto quer dizer?" (2003, p.469).

A partir dessas reflexões este trabalho propõe ler a obra Caim, de José Saramago, privilegiando aspectos relevantes quanto ao modo de construção e organização textuais para perceber, no diálogo estabelecido com o texto bíblico do qual se apropria, como este último é transgredido e atualizado para contextos diversos. 
O livro de Saramago (re)conta a história de Caim. Depois do assassinato do irmão Abel, Caim é marcado por Deus e destinado a viver como errante pelos tempos. Nesse trânsito pelos tempos Caim presencia/vivencia alguns episódios bíblicos do Antigo Testamento e, como testemunha ocular do que ocorria nas cidades, palácios, campos de batalha torna-se um grande questionador das atitudes e decisões de Deus sobre a terra, estabelecendo um embate mordaz com o Criador.

Primeiramente, é interessante observar como o livro de Saramago transita pelos textos bíblicos e o diálogo que estabelece com o discurso religioso. A grande maioria dos textos retomados pelo romance refere-se aos livros de Gênesis, Êxodo e Josué, histórias que, passadas oralmente de geração a geração, foram fixadas pela escrita e sacralizadas pela religião cristã. Há, inclusive, no livro, uma referência às histórias passadas adiante, o que já derruba a ideia de uma verdade única relativa aos textos bíblicos:

De muitas destas histórias não poderia Caim, obviamente, ter sido testemunha directa, mas algumas, quer fossem verdadeiras ou não, chegaram ao seu conhecimento pela sabida via de alguém que o havia ouvido de alguém e o veio contar a alguém. (2009, p.102).

Composto por poemas, crônicas, cânticos, provérbios, o Antigo Testamento pode ser comparado a uma epopeia. O conteúdo da epopeia, como se sabe, carregava o estatuto de não poder ser contestado, configurando-se como um tipo de verdade absoluta. Nesse sentido, Caim já apresenta uma primeira transgressão quando, ao se apropriar dos textos bíblicos, subverte o discurso religioso introduzindo acréscimos e intervenções de várias ordens. 
Tais textos são utilizados para um fim diferente, o da crítica, o que se percebe no modo mesmo como as histórias são narradas, cujo tom aparece investido de chacota e injúria, tocando no que seria considerado intocável. A história narrada em Caim é mais uma história que pode ser contada entre várias outras, o que coloca em causa o estatuto de verdade veiculado pelo discurso religioso:

Dos escritos em que, ao longo dos tempos, vieram sendo consignados um pouco ao acaso os acontecimentos destas remotas épocas, quer de possível certificação canônica futura ou fruto de imaginações apócrifas e irremediavelmente heréticas, não se aclara a dúvida sobre que língua terá sido aquela, se o músculo flexível e húmido que se mexe e remexe na cavidade bucal e às vezes fora dela, ou a fala, também chamada idioma, de que o senhor lamentavelmente se havia esquecido e que ignoramos qual fosse, uma vez que dela não ficou o menor vestígio, nem ao menos um coração gravado na casca de uma árvore com uma legenda sentimental, qualquer coisa no gênero amo-te eva. (SARAMAGO, 2009, p.10).

Vale realçar que a religião é um dos mecanismos utilizados no processo civilizatório com vistas a inibir transgressões de comportamento julgadas socialmente inaceitáveis, além de carregar a prerrogativa de estabilizar as emoções humanas, justamente pela promessa de vida eterna. É assim que, ao longo do tempo, a religião fixou algumas verdades absolutas no sentido de moldar o comportamento humano, preconizando a obediência aos mandamentos divinos e o cultivo dos bons sentimentos e da boa conduta, como preparação para alcançar a vida eterna e se encontrar definitivamente com Deus. Não por acaso, o texto bíblico 
mostra que muitos dos conflitos, guerras, perdas e sofrimentos humanos são resultado do castigo divino pela desobediência aos ensinamentos de Deus. Ao retomar esses textos Caim realça questões que são próprias do homem não só em relação a guerras e conflitos, mas à bondade, à maldade, à luta pelo poder, elementos que engendram as próprias relações sociais. Bem e mal são postos como constituintes de todo ser, humano e até mesmo divino, já que no livro Deus também é investido de maldade e insensatez:

Eu não fiz mais que matar um irmão e o senhor castigou-me, quero ver agora quem vai castigar o senhor por estas mortes, pensou caim, e logo continuou, Lúcifer sabia bem o que fazia quando se rebelou contra deus, há quem diga que o fez por inveja e não é certo, o que ele conhecia era a maligna natureza do sujeito. (SARAMAGO, 2009, p.101).

Ao que parece, o romance de Saramago derruba uma questão inerente ao mito - e aqui se fala do mito religioso - que é a não possibilidade de diálogo, uma vez que o mito procura explicar a realidade, apresentando respostas prontas, nas quais não cabe reformulação. Ao retomar a história bíblica para contála de outro jeito, pode-se dizer que Caim propõe um diálogo. Entretanto, parece que a perspectiva adotada no livro é muito mais dialética que dialógica, já que mostra apenas um ponto de vista, nitidamente contrário ao discurso religioso. Percebese, inclusive, a forte presença autoral interferindo na narrativa: "[...] Por motivos que não está nas nossas mãos dilucidar, simples repetidores de histórias antigas que somos, passando continuamente da credulidade mais ingênua ao cepticismo mais resoluto [...]" (2009, p.102). 
Entretanto, mesmo que o ponto de vista adotado pareça estar muito mais próximo de uma crítica contestatória, por vezes até esbarrando em certo proselitismo - o que não é de se estranhar quando se recorre à pessoa do autor - não se pode retirar da obra o seu valor em relação ao modo de narrar e às estratégias usadas na construção do texto, dos personagens e da proposta transgressora que se liga não só ao nível do conteúdo, mas da própria linguagem que transgride regras e realidades das quais se apropria para delas dizer.

Há passagens do livro que podem, sim, colocar-se em diálogo com outros contextos e outros discursos. Por exemplo, quando o livro toca na questão filosófica que diz respeito à angústia do homem por não saber quem realmente é, o que o leva a uma incessante busca por respostas. Em muitos momentos da narrativa a personagem procura o entendimento para certas coisas com as quais se depara, questionando e pedindo respostas que nem sempre existem:

Matei o meu irmão. Se os tempos fossem outros, talvez tivesse chorado, talvez se tivesse desesperado...mas sendo as coisas o que são, praticamente o mundo só agora foi inaugurado, faltam-nos ainda muitas palavras para que comecemos a tentar dizer quem somos e nem sempre daremos com as que melhor o expliquem... (SARAMAGO, 2009, p.42).

No trânsito de Caim pelos tempos e espaços e diante dos questionamentos que faz, a narrativa vai desmanchando o discurso religioso. Em sua errância Caim percebe que não há nada fixo ou definitivo. Ironicamente, é o próprio Deus, em sua fala, que também 
sinaliza quanto à incerteza da existência de uma verdade absoluta que possa ser encontrada na religião ou no mito: "[...] os deuses são como poços sem fundo, se te debruçares neles nem mesmo a tua imagem conseguirás ver [...]" (SARAMAGO, 2009, p.153).

Interessante é pensar, também, no confronto entre os gêneros: de um lado, o mito religioso que opera no sentido de estabelecer verdades que devem ser aceitas como absolutas; é um movimento que se faz de fora para dentro. De outro lado, o romance: gênero por natureza inacabado, que mais pergunta do que responde, que deixa as coisas em aberto e que representa a própria angústia do homem em relação à sua existência. O movimento, aí, inverte-se, pois vem de dentro (do homem) para fora. Assim, o livro se vale do mito bíblico para provocar o seu desmanche através de outro gênero, o romance. Dito de outra forma, o profano mancha o sagrado.

Como algo que também não é definitivo, a própria identidade de Caim vai sendo (re)construída. À medida que testemunha acontecimentos e vive as mais diversas experiências, a personagem despe-se da culpa anteriormente imposta a ele por Deus e, de réu e condenado, passa a interlocutor que não só julga, mas contesta as atitudes daquele, colocando em causa um poder exagerado a ele atribuído:

[...] onde é que nasceu essa peregrina ideia de que deus, só por ser deus, deva governar a vida íntima de seus crentes, estabelecendo regras, proibições, interditos e outras patranhas do mesmo calibre?... (SARAMAGO, 2009, p.158-159).

Ao longo da narrativa vários deslocamentos são operados. Interessante é que o livro se inicia justamente com a cena de 
Deus dotando Adão e Eva de linguagem. É a partir daí que o romance, como linguagem, vai deslocando e tirando do lugar aquilo que se supunha já fixo e determinado, como faz com o texto/discurso do qual se apropria. Ao introduzir a linguagem cotidiana, próxima do homem comum, o romance derruba 0 tom de grandiosidade do texto/discurso religioso. Ocorre uma atualização do texto bíblico, já que as histórias são contadas de outro jeito, utilizando-se uma linguagem comum, sem rebuscamentos e mais próxima do leitor, como se o narrador estivesse contando oralmente a história de Caim. É a própria linguagem que explica tal opção, quando se volta para si mesma num movimento metalinguístico:

[...] as palavras têm os seus quês, os seus comos e os seus porquês. Algumas, solenes, interpelam-nos com ar pomposo, dando-se importância, como se estivessem destinadas a grandes coisas, e, vai-se ver, não eram mais que uma brisa leve que não conseguiria mover uma vela de moinho, outras, das comuns, das habituais, das de todos os dias, viriam a ter, afinal, conseqüências que ninguém se atreveria a prever, não tinham nascido para isso e, contudo abalaram o mundo. (SARAMAGO, 2009, p.52).

Comentários, reflexões e interferências do narrador, em sua maioria de cunho irônico, aparecem constantemente entremeados à narrativa:

Agora somente nos interessa a família de que o papá adão é cabeça, e que má cabeça foi ela, pois não vemos como chamar-lhe doutra maneira, já que bastou trazer-Ihe a mulher o proibido fruto do conhecimento do bem e do mal para que o inconseqüente primeiro dos patriarcas, depois de 
se fazer rogado, em verdade mais por comprazer consigo mesmo que por real convicção, se tivesse engasgado com ele, deixando-nos a nós, homens, para sempre marcados por esse irritante pedaço de maçã que não sobe nem desce. (SARAMAGO, 2009, p.14-15)

O deslocamento também se dá em relação ao leitor que, retirado do lugar de conforto da leitura linear e encadeada, experimenta o estranhamento causado pelo texto, tanto em relação ao desmanche do texto bíblico como algo sagrado, quanto em relação à própria escrita: pontuação precária, parágrafos longos, diálogos misturados no corpo da narrativa, sem marcação, o que quebra a maneira usual de leitura: "[...] Revolveu-se o senhor contra a mulher e perguntou, Que fizeste tu, desgraçada, ela respondeu, A serpente enganoume e eu comi, Falsa, mentirosa, não há serpentes no paraíso [...] (SARAMAGO, 2009, p.17).

Há, ainda, além das idas e vindas de Caim, num movimento de embaralhamento de tempos, as antecipações de fatos feitas pelo narrador que ainda não aconteceram, o que rompe com a forma tradicional de se apresentar um enredo, quando se espera que as coisas aconteçam no seu devido tempo. Na seguinte passagem o narrador já antecipa qual será a atitude de Noah em relação a seu plano de matar Caim: "[...] Sonhos, fantasias, delírios, noah não matará ninguém e terá ele próprio a sorte de escapar à morte sem fazer nada por isso." (SARAMAGO, 2009, p.62).

Como num tipo de recurso retórico, o leitor é envolvido o tempo todo na narrativa, muitas vezes incluído na fala do narrador, como se compactuasse com a perspectiva deste: "[...] Precisava de um burro, ainda que tivesse de o roubar, mas nós, que o 
vamos conhecendo cada vez melhor, sabemos que não o fará." (SARAMAGO, 2009, p.143).

O movimento de deslocamento ocorre, também, em relação à imagem de Deus: o todo poderoso e onipotente que aparece no início do livro: "[...] Eu sou o senhor, gritou, eu sou aquele que é. [...]" (SARAMAGO, 2009, p.16), vai sendo, no decorrer da narrativa, colocado ao lado do homem comum, até ocupar um lugar de igualdade. Há uma dessacralização do divino; Deus é colocado no mesmo nível do humano, enfraquecido em seu poder de comandar e determinar o destino dos homens:

[...] é que a vida de um deus não é tão fácil quanto vocês crêem, um deus não é senhor daquele contínuo quero, posso e mando que se imagina, nem sempre se pode ir direito aos fins, há que rodear, é verdade que pus um sinal na testa de Caim, nunca o viste, não sabes quem ele é, mas, o que não se compreende é que não tenha poder suficiente para o impedir de ir aonde sua vontade o leve e fazer o que entender... (SARAMAGO, 2009, p.119).

Em outra passagem ocorre a mesma inversão de papéis quando um anjo, atraído sexualmente por Eva, é colocado no mesmo nível do humano:

A espada silvou com mais força como se tivesse recebido um súbito afluxo de energia, a mesma energia que levou o querubim a dar um passo em frente, a mesma que o fez erguer a mão esquerda e tocar no seio da mulher. [...]". (SARAMAGO, 2009, p.25).

O texto também se constrói como lugar de trânsito de vozes que se cruzam ao longo de toda a narrativa. À voz do narrador se 
mistura a voz da personagem: "[...] Bem, tudo isso pode ser certo, mas o que ninguém me explica é a razão de as nuvens não poderem passar de lá para cá. A não ser, diz a voz que fala pela boca de Caim, que o tempo seja outro [...] (SARAMAGO, 2009, p.77). Da voz dos anjos ecoa a voz do senso comum religioso: "[...] Os desígnios de deus são inescrutáveis [...]" (2009, p.135). Por vezes, a voz autoral se confunde com a voz do próprio narrador: "[...] Ao terceiro, como também ficou dito, chamaram-lhe set, mas esse não entrará na narrativa que vamos compondo passo a passo com melindres de historiador [...]" (2009, p.14). A cultura popular também é evocada através do uso de ditos populares: "[...] digamos que o engano, repetindo a voz popular, é como o comer e o coçar, a questão é começar. [...]" (, 2009, p.99).

Ao atualizar a linguagem do texto bíblico, o romance atualiza também contextos. Apesar de se valer de relatos muito antigos, o modo como estes são recontados traz à cena situações comuns que fazem parte da dinâmica das sociedades, a exemplo das relações de trabalho: “[...] Podes começar a trabalhar já, eu levo-te à pisa do barro, Quanto vou ganhar, perguntou caim [...]" (SARAMAGO, 2009, p.48); da rotina do casamento: "[...] Em situações como esta, há quem defenda que o nascimento de um filho pode ter efeitos reanimadores, senão da libido...ao menos dos sentimentos [...] (2009, p.12); da presença de sinais que remetem ao progresso da cidade moderna: "[...] faltam aqui os automóveis e os autocarros, os sinais de tráfego, os semáforos, as passagens subterrâneas, os anúncios... numa palavra, a modernidade [...]" (2009, p.47). Ao misturar esses contextos no contexto bíblico o livro tira de foco as coisas que estão longe 
do homem para apresentar situações cotidianas com as quais o homem tem que lidar.

De certa forma, o romance também toca nas relações familiares ao mostrar, por exemplo, o sentimento de ciúme que envolve os dois irmãos na disputa pelo amor do pai, representado pela figura de Deus. Por outro lado, a autoridade paterna é questionada e colocada em crise com a perda da autoridade e do poder de Deus quando este é igualado aos homens.

O que se coloca, também, em causa é a posição do homem na sociedade machista, abalada pela ascensão social da mulher. Exemplo disso é a cena em que Adão tenta impor sua voz de autoridade diante da decisão de Eva em buscar, junto ao anjo, alimento para saciar a fome: "- Mas não te esqueças de quem manda aqui sou eu". Desafiando as ordens do marido, Eva se sente, enfim, liberta de sua autoridade: "[...] Estava surpreendida consigo mesma, com a liberdade com que tinha respondido ao marido... Era como se dentro de si habitasse uma outra mulher [...]" (SARAMAGO, 2009, p.23). O novo lugar ocupado pela mulher também se mostra na figura de Lilith que, sem perder sua feminilidade e poder de sedução, assume o lugar masculino no comando da cidade. A própria relação de Caim e Lilith derruba pré-conceitos do senso comum em relação a valores familiares tradicionais, como o relacionamento extraconjugal e a infidelidade.

Interessante, ainda, é a mudança de posição que se observa em relação à personagem Caim. É ele, tido como o mais fraco, o errante, o homicida, o que estaria, a princípio, ocupando um lugar à margem, quem tece a narrativa. O livro dá voz justamente à 
voz que se calou na história bíblica, já que após matar Abel e ser condenado a vagar pelo mundo, Caim não mais aparece no Antigo Testamento. No romance há uma inversão de posições: à medida que a personagem transita pelos tempos e vive experiências as mais diversas, ele ganha força e autonomia para narrar a história bíblica a partir de outra perspectiva, tensionando e até mesmo colocando em causa o discurso religioso. É outra história que desmancha, ou pelo menos mancha, a história religiosa oficial. Ironicamente, o livro faz referência a isso na fala do próprio Deus quando, admitindo sua incapacidade no controle absoluto do mundo e dos homens, ordena a Josué qual versão da história deverá prevalecer para registro futuro: “[...] Não falarás a ninguém sobre o que foi tratado aqui entre nós, a história que virá a ser contada no futuro terá de ser a nossa e não outra, Josué pediu ao senhor que detivesse o sol e ele assim fez, nada mais [...]" (SARAMAGO, 2009, p.119-120).

Tudo isso pode ser relacionado à questão do conhecimento, pois conhecendo é que o homem passa a questionar. Assim ocorre com Caim: quando conhece o modo como Deus agia e decidia as coisas e o que os homens eram capazes de fazer em nome de uma fé e de uma promessa de vida eterna, ele passa da posição de passividade à de questionamento e contestação. Questionamento e contestação que não têm fim. Apesar de o fim da viagem da arca coincidir com o fim do livro e com o fim da própria humanidade, já que na perspectiva de Caim não valia a pena um recomeço, o final fica em aberto; a história não se fecha, dando a entender que na eterna discussão entre deus e o homem, prevalecerá a ausência de respostas ou verdades absolutas. 
Ao protagonizar a história de Caim, o livro de Saramago protagoniza a história do próprio homem em sua errância. E é por ser um ser "errante" que não se pode impor ao homem uma única verdade, uma única história, uma única identidade.

\section{REFERÊNCIAS}

BAKHTIN, Mikhail (1981). "A interação verbal". In: Marxismo e filosofia da linguagem: problemas fundamentais do método sociológico na ciência da linguagem. São Paulo: Editora Hcitec. p.110-127.

BENVENISTE, Émile (2005). "Da subjetividade na linguagem". In: Problemas de lingüística geral I. Campinas, SP: Pontes Editores. p.284-293.

BOSI, Alfredo (2003). "A interpretação da obra literária". In: Céu, inferno: ensaios de crítica literária e ideológica. ed. 34. São Paulo: Duas Cidades. p.461-479.

ISER, Wolfgang. "Os atos de fingir, ou o que é fictício no texto ficcional" (1983). In: LIMA, Luiz Costa . Teoria da literatura em suas fontes, vol. II, Rio de Janeiro: Francisco Alves.

(1996). O fictício e o imaginário - perspectivas de uma antropologia literária. Rio de Janeiro: Editora da UERJ.

. (2002). "O jogo do texto". In: LIMA, Luiz Costa (org.). A literatura e o leitor: textos da Estética da Recepção. 2.ed. revista e ampliada. São Paulo: Paz e Terra, p.106-118.

MORAIS, Márcia Marques. "Ensino de/com literatura: objetivos e desafios". Jornal Estado de Minas, Belo Horizonte/MG, 01-01. In www.ich.pucminas.br/ posletras/publicacoes.htm Acesso em 06.Mar.2004.

SARAMAGO, José (2009). Caim. São Paulo: Companhia das Letras.

WALTY, Ivete; PAULINO, Graça (2005). "Leitura literária: enunciação e encenação". In: MARI, Hugo et al. Ensaios sobre leitura. Belo Horizonte: Editora da PUC Minas. p.138-154. 